\title{
The effect of religion on parenting in order to guide parents in the way they parent: a systematic review
}

\author{
Mervyn Ronald Petro, Edna Grace Rich, Charlene Erasmus and Nicolette Vanessa Roman
}

\begin{abstract}
Religion has a growing influence on parenting, and there remains a need to understand the influence of religious values in order to inform parents, and other professional bodies, on how religious beliefs can influence child-rearing practices. A systematic review was conducted to explore relevant articles during the time period 2004-2014. The aim of the review was to explore the effect of religion on parenting, and to establish effective ways in which religious parents can be guided in parenting. The findings show that religion does influence parenting, and that with intervention aimed at increasing specific skills, parenting practices may improve.
\end{abstract}

\section{Background}

Parenting practices refer to the actual behavior of parents toward their children such as spanking, helping them with their homework, showing an active interest in their activities, and so forth. Parenting practices may be viewed as specific behavior with a view to specific socialization goals (Vermeer, Jansen, \& Scheepers, 2012). Despite an increased interest in parenting in all sectors of society, the research base that informs under- standing of religion in family life remain limited (Coleman, 1997; Mahoney, Pargament, Tarakeshwar, \& Swank, 2001). The horror of September 11, 2001, at the World Trade Center in New York, has reignited distrust towards those subscribing to strong religious beliefs (Nye \& Weller, 2012). At the same time, this event contributed to the renewed interest of scholars, professionals, and policymakers alike in the exploration of the impact that religion has on different facets of believers' lives, especially in countries (such as the United Kingdom) that are undergoing progressive secularization (Brown, 2009; Mahoney, 2010).

Although generally suggestive of a positive impact of religiosity on parenting, Mahoney et al. (2001) pointed out that effect sizes are typically small and that studies generally suffer from methodological problems. This does, however, suggest a positive impact of religiosity on parenting. Studies that do sample parents often only include mothers so that it is unclear whether the findings replicate across parental gender (Duriez, Soenens, Neyrinck, \& Vansteenkiste, 2009). 
However, a study by Wilcock (2002) suggested that religion does play a role in shaping men's commitment to their children. Religious teaching, however, emphasizes that both men and women play a central role in family life. According to Volling, Mahoney, and Rauer (2009), religious fathers are involved in a culture that shapes their values and behaviors by emphasizing the importance of family relationships and a commitment to others that encourages them to be actively involved in the lives of their children.

Religious beliefs, however, continue to generate unease, lack of genuine engagement, a "low level of acceptance" (Furman, Benson, \& Canda, 2004, p. 813), and disrespect amongst scholars as well as within ranks of professionals, including social workers (Hodge, 2005; Streets, 2009; Thyer \& Myers, 2009; Whiting, 2008). There is a good deal of historical evidence to suggest that religion possesses the capacity to socialize, motivate, constrain, and direct human behavior (Smith, Denton, Faris, \& Regnerus, 2002; Smith, 2003). These direct effects are not the only way that religion influences human action, but they are the most straightforward way (Regnerus \& Smith, 2005). Despite ample evidence that global indexes of religiousness are linked to family functioning, the mechanisms by which religion uniquely influences family dynamics are not well understood or empirically documented (Pargament, 2005).

In a recent review of 75 papers about religion and family life (Howard \& Lees, 2007), the most common areas for research were the transmission of religious beliefs between parents and children and identifying ways in which religious beliefs and practices informed approaches to parenting. Furthermore, professionals responsible for safeguarding and promoting the welfare of children are said to have little awareness or training as to the role of religion in family life, with many professionals unsure about dealing with the influence of faith on parenting (Frosh, 2004; Gilligan \& Furness, 2006; Kelly \& Sinclair, 2005). Not much is known about the developmental trajectories of children reared in religious families; without this knowledge, we do not know if there are advantages or disadvantages to being brought up with religious beliefs and practices (Frosh, 2004; Phoenix \& Husain, 2007).

Parent's use of religious coping and family religious behavior, defined as attendance at religious or spiritual programs, predicted several aspects of child well-being above and beyond parenting styles. These effects were small, but significant. It is interesting that family attendance at religious or spiritual programs was associated with greater child wellbeing, including better child health, social skills rated by a parent, and fewer internalizing behavior problems (Michelle et al., 2007). It is widely accepted that how parents relate to their children are of crucial importance not only for their children's wellbeing, but also for their internalization of values (Baumrind, 1996; Dudley, 2000; Eisenberg, Zhou, Spinrad, Valiente, Fabes, \& Liew, 2005).

The emotional context of childrearing forms the second dimension of the integrative model of parenting (Darling \& Steinberg, 1993; Eisenberg et al., 2005). There is conflicting evidence as to whether parental commitment to religious beliefs is likely to result in a 
harsh or warm parenting style (Gershoff, Miller, \& Holden, 1999; Wilcox, 1998); Bartkowski \& Wilcox, 2000; Mahoney, 2010). Padilla-Walker and Thompson (2005) established that religious values have a stronger impact on parenting tendencies than any other values that parents hold. Religion and parenting is an under-researched area (Frosh, 2004; Phoenix \& Husain, 2007). In the past, practitioners have tended to consider religion as an "add-on" when exploring parenting, or believed that the value systems are similar when it comes to child rearing. However, the need to know about these influences is increasing. Parenting nevertheless may be significantly improved with interventions aimed at increasing specific skills and promoting greater understanding for the underlying motivations of a child's behavior. Various models of parent training have been developed and research continues to evaluate the effectiveness of specific programs for addressing a range of problems.

There is a need for a systematic examination of parental values and goals of parenting that acknowledges the cultural and religious diversity of citizens alongside an exploration of the impact that a distinctive religious context has on children and young people growing up (Padilla-Walker \& Thompson 2005). The aim of this systematic review was to explore the effect of religion on parenting, establish effective ways in which religious parents can be guided in parenting and to critically appraise the methodological quality of the studies related to the effect of religion on parenting in order to guide parents in the way they parent.

\section{Methods}

\section{Study eligibility criteria}

A PRISMA flowchart (Figure 1) was created to illustrate study identification, screening, eligibility, inclusion, and analysis. A minimum of two reviewers performed the initial identification of studies, the secondary screening of studies, and final determination of eligibility and study inclusion. The types of studies that were included in this systematic review were related to the purpose of the study (a priori; i.e., "the effect of religion on parenting in order to guide parents in the way they parent"). Restricting language in systematic reviews remains controversial. Some studies have suggested that systematic reviews that include only English language publications tends to overestimate effect sizes (relative strength of the individual study's results) whereas other studies suggest that language restriction may not do so (Shea et al., 2007). Only English studies were included. Lipsey and Wilson (2001) stated that studies that are reported in languages other than English are doing so simply because of the practical difficulty of translation. 


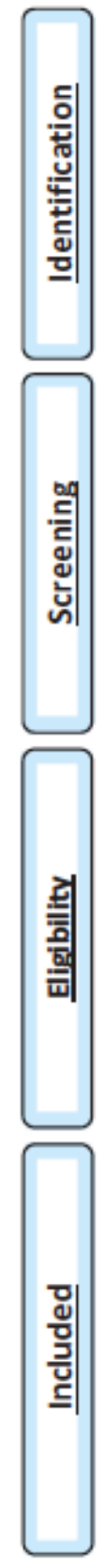

$$
\begin{gathered}
\text { \# of records identified through } \\
\text { database searching } \\
(n=78)
\end{gathered}
$$$$
\text { \# of additional records identified }
$$$$
\text { through other sources }
$$$$
(n=0)
$$
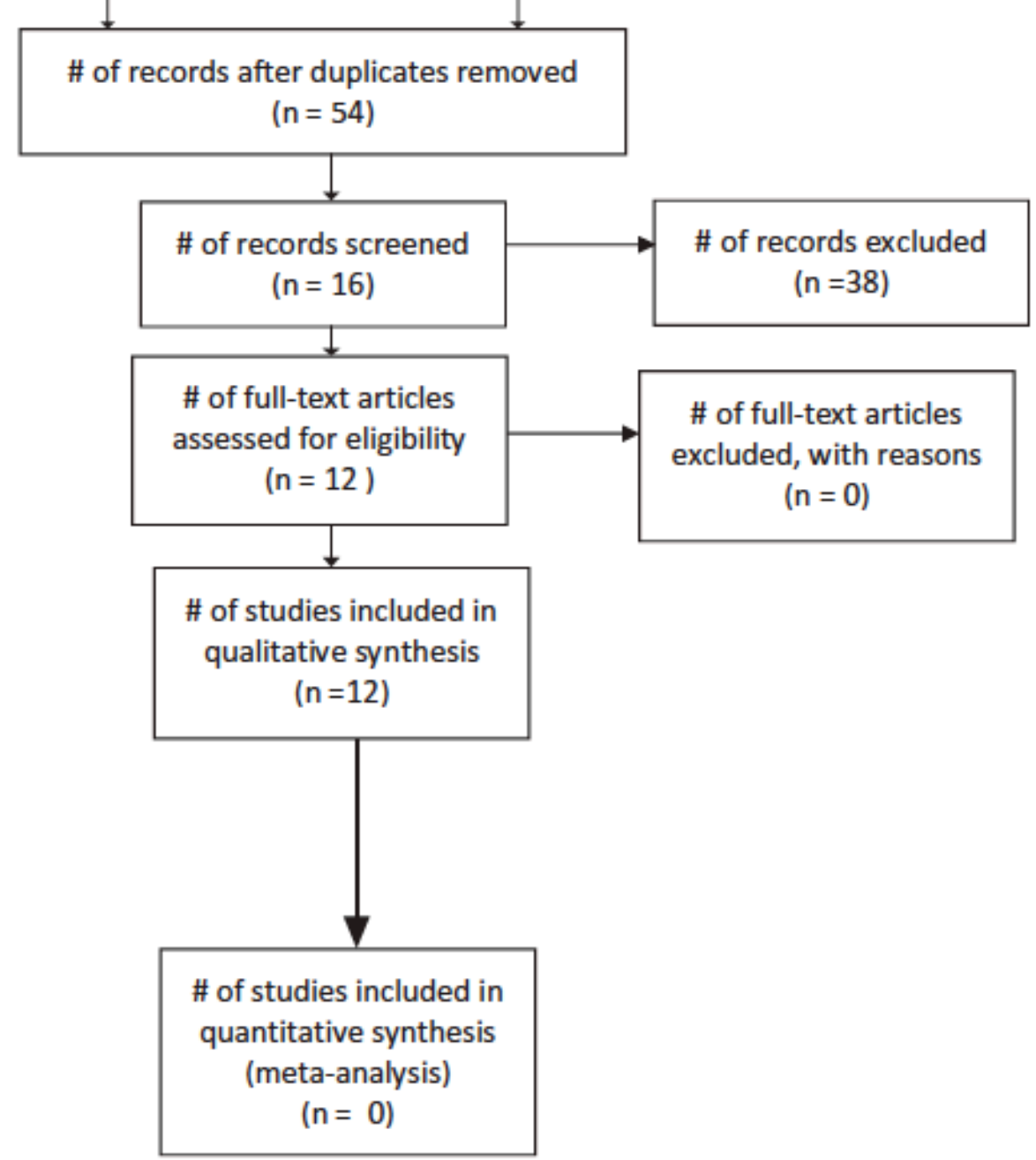

Figure 1. PRISMA Flowchart (Moher et al., 2009).

Full text peer-reviewed journals, published in English between 2004 and 2014, were included. Both primary and secondary articles were included; reference lists of studies were used to find additional articles. The full text of the report was necessary to ensure the accuracy of decisions to include or exclude studies from the reference lists of candidate studies. Duplicates were excluded. Article exclusion is applicable when authors publish more than one article-usually with different lengths of follow-up or with analysis and reporting of a different primary or secondary outcome (Harris, Quatman, Manring, Siston, \& Flanigan, 2013). 


\section{Search strategy}

For this systematic review, a widespread literature search was conducted using library and electronic databases. Online library databases and published research reports and journals available at the University of the Western Cape were accessed. Electronic databases accessed were Jstor, SAGE Journals, Wiley, Ebscohost, and PsyArticle. Electronic databases offer access to vast quantities of information, which can be retrieved more easily and quickly than using a manual search (Younger, 2004). In finding the articles, databases were accessed followed by an analysis of text words contained in the title, abstract, and in the index terms used to describe the article. Keyword descriptors were used in searching within the aforementioned online databases. Keyword searches are the most common method of identifying literature (Ely \& Scott, 2007). The keywords used to identify the terms were: "effect(s) of religion on parenting."

In searching for applicable articles that are specifically related to the topic the search engines were limited to search for full text, peer-reviewed journals published in English only. The "advanced search" feature in the databases was used to set specific criteria. The time period was limited from 2004-2014 to get the most current research articles. The initial resources were selected by reviewing the article abstracts and then determining if the contents were relevant to the keywords. The same keywords were used for all databases. If the article appeared to meet the inclusion criteria, the full paper was retrieved. A detailed ongoing record of all searches was maintained in a Microsoft Excel spreadsheet form which included: databases searched plus the specific years or other limitations specified; keywords used for each database; total number of articles displayed (hits) for each search strategy; and number of articles that met the inclusion criteria and that were selected. Also included were any duplicates found in the different database searches. Figure 1 shows a flow diagram of the results of the search strategy implemented.

\section{Study and data collection processes}

The process of reviewing involved the principal investigator and his super- visor, as the reviewing process should be done by two reviewers. Originally, the search was conducted by the principal investigator and sent to the supervisor, who also reviewed and screened the abstracts and titles. Mechanisms need to be in place to help resolve disagreements among reviewers. Typically, resolution is achieved through a process of discussion between the reviewers but if this is unsuccessful other reviewers can also become involved. The next stage was to examine each of the studies deemed to be relevant to the review question in order to reach some conclusions about the quality of each study included. 
Table 1. Scoring Sheet for the Critical Appraisal.

\begin{tabular}{lcccccccccc}
\hline Author & 1 & 2 & 3 & 4 & 5 & 6 & 7 & Score & $\%$ & Grade \% \\
\hline Vermeer et al., 2012 & 1 & 0 & 0 & 1 & 1 & 1 & 1 & $5 / 7$ & 71 & $67-100$ \\
Petts, 2009 & 1 & 0 & 0 & 1 & 1 & 1 & 1 & $5 / 7$ & 71 & $67-100$ \\
Horwath et al., 2008 & 1 & 0 & 1 & 1 & 1 & 1 & 1 & $6 / 7$ & 86 & $67-100$ \\
Godina, 2014. & 0 & 0 & 0 & 1 & 1 & 1 & 1 & $4 / 7$ & 57 & $33-66$ \\
Lees and Howarth, 2009 & 1 & 0 & 0 & 1 & 1 & 1 & 1 & $5 / 7$ & 71 & $67-100$ \\
Bader and Scott, 2006 & 1 & 0 & 1 & 1 & 1 & 1 & 1 & $6 / 7$ & 86 & $67-100$ \\
Mahoney et al., 2001 & 0 & 0 & 1 & 1 & 1 & 1 & 1 & $5 / 7$ & 71 & $67-100$ \\
Regnerus and Burdette, 2006 & 0 & 0 & 1 & 1 & 1 & 1 & 1 & $5 / 7$ & 71 & $67-100$ \\
Duriez et al., 2009 & 1 & 0 & 0 & 1 & 1 & 1 & 1 & $5 / 7$ & 71 & $67-100$ \\
Nye and Weller, 2012 & 1 & 0 & 0 & 1 & 1 & 1 & 1 & $5 / 7$ & 71 & $67-100$ \\
Padilla-Walker and Thompson, 2005 & 0 & 0 & 1 & 1 & 1 & 1 & 1 & $5 / 7$ & 71 & $67-100$ \\
Furman et al., 2004 & 1 & 0 & 0 & 1 & 1 & 1 & 1 & $5 / 7$ & 71 & $67-100$ \\
\hline
\end{tabular}

\section{Methodological quality assessment}

Rating scales that assess methodological quality provide the means to critically appraise the literature. Critical appraisal of the methodological quality of primary studies is an essential feature of the systematic review. There is no existing consensus on the ideal checklist and scale for assessing methodological quality.

Different research fields and/or different study design types have different methodological quality assessment tools. The internal validity can be influenced by selection bias, performance bias, detection bias, attrition bias, reporting bias, and other biases during the research process. Therefore, all methodological quality assessment tools are focused on these aspects, to minimize "risk of bias," as recommended by the Cochrane Handbook for Systematic Reviews of interventions (Higgins \& Green, 2011). Each included study was appraised for internal validity (study quality assessment) using a standardized approach for rating the quality of the individual studies. Ideally, this should be done by at least two independent reviewers appraising each study for internal validity. However, a single commonly accepted, standardized tool for rating the quality of studies does not exist. Critical appraisal tools provide analytical evaluations of the quality of the study. A critical appraisal tool for assessing the methodological quality of studies was adapted from other research (Roman \& Frantz, 2013). See Appendix for an example of the critical appraisal tool that was adapted from Roman and Frantz (2013).

\section{Method of appraisal}

An initial review was conducted by the principal investigator followed by a review of abstracts from the additional reviewers. Each reviewer had appraised the articles according to the critical appraisal tool. Results were compared and differences were discussed with a final decision thereafter. These discussions lead to decisions on which articles should be included for the final review. A rating scale was made, using the appraisal tool and a cut off score was determined. 
The methodological quality scores obtained by the articles prior to final inclusion are illustrated in the table below. Generation of a PRISMA flowchart (Figure 1) that demonstrates the identification and screening of potentially eligible studies determines the final number of studies included for analysis. A flowchart of the process is presented in Figure 1 as recommended by PRISMA statement (Moher, Liberati, Tetzlaff, \& Altman, 2009).

\section{Results}

\section{Data extraction}

Once all exclusion criteria are applied and the final list of studies is identified for analysis, there are several effective methods of extraction of study data into a coherent group of PICOS parameters. These data collection forms can be either written paper checklists or electronic spreadsheets (Harris et al., 2013). The purpose of data extraction is to describe the study in general, to extract the findings from each study in a consistent manner in order to enable later synthesis, and to extract information to enable quality appraisal so that the findings can be interpreted. Data extraction appears, at first glance, to be a relatively straightforward component of a systematic review. In practice, the approach used may have a significant impact on the review findings through shaping the range of data feeding.

\section{Search results}

Initial searches of electronic databases (Google Scholar) generated 19,300 possible articles, which were then reviewed for relevance. Eventually 10 articles were deemed of sufficient relevance and selected for data extraction. These articles were selected based on the inclusion criteria of articles that are relevant to the research keyword phrase: "the effect of religion on parenting." Only articles in English between the period 2004 and 2014 were considered. The data extraction table headings consist of demographic information such as author, study design, country, population, sample size, and description of study design as well as the objectives of this systematic review, namely, description of religion, description of parenting, and the effect of religion.

From the 10 selected articles that were appraised, data extraction followed. The data for the systematic review contains the results from individual studies. Before analyzing the data, data needs to be extracted from the primary research. The data extraction sheet identifies relevant demographic information such as authors, study design, population, sample size, and country, as well as the objectives of this systematic review. The data extrac- tion table was developed in order to orderly record the extracted information relevant to the research objectives in an orderly manner. A full summary list of these studies is given in Table 2.

\section{Description of included studies}

It is clear from the data extraction table (Table 2) that most of the research studies done on this issue are longitudinal (four) and cross-sectional (five). The research undertaken consisted mostly of systematic literature reviews in the form of longitudinal surveys and 
interviews. Eight of the studies were done in the United States, one in France, and one in the United Kingdom. In most of the studies done, the majority of the population sample was White adolescents and parents from mainline Protestant, Catholic, and affiliated denominations. However, some research included other races and religions namely, Muslims, Hispanics, and African American religious families and parents. The most common areas for research were the transmission of religious beliefs between parents and children and identifying ways in which religious beliefs and practices informed approaches to parenting.

Godina (2012) researched adult participants who were brought up by Seven-Day Adventist parents. She found that there was a strong sense that parents were themselves committed to a lifestyle that was shaped by the main tenets of Adventist doctrine and were expecting the same from their children. Armet (2009) showed that parenting styles oriented to socialize children to accept religious values and norms are framed by the mutual reinforcing relationship between the family and religious institutions. Mahoney, Pargament, Murray-Swank, and Murray-Swank (2003) found the belief that family relationships are imbued with sacred qualities or connected to God, and that by studying these cognitions scientists can began to understand the ways in which religion affects family life. Volling et al. (2009) stated that when parents believe their parental role is sanctioned by God, they may use religious justification as a means of supporting what is right and wrong for their children. Petts's (2011) research results suggested that children being raised by a parent/parents who believe that religion is important to family life are associated with higher well-being. Bridges and Moore's (2002) study showed that parents' religiosity may influence behavior and beliefs that they model for their children. Power and McKinney's (2013) survey amongst college students found that parents who have a strong faith and high religious well-being are likely to transmit their religiosity to their children directly. Wilcox's (2002) study showed that religion does play a role in shaping men's commitment to their children and that religion is related to paternal involvement. 


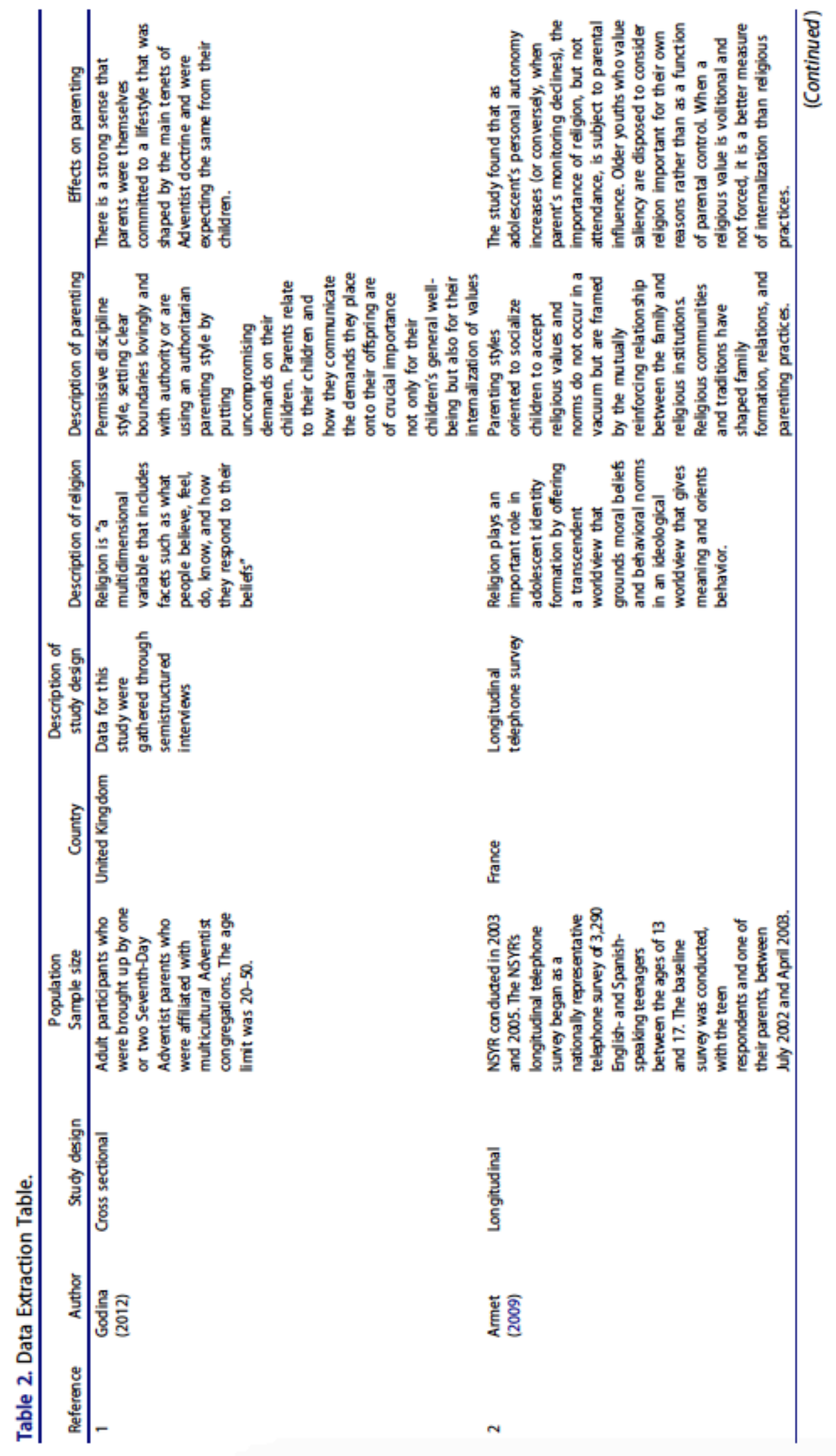




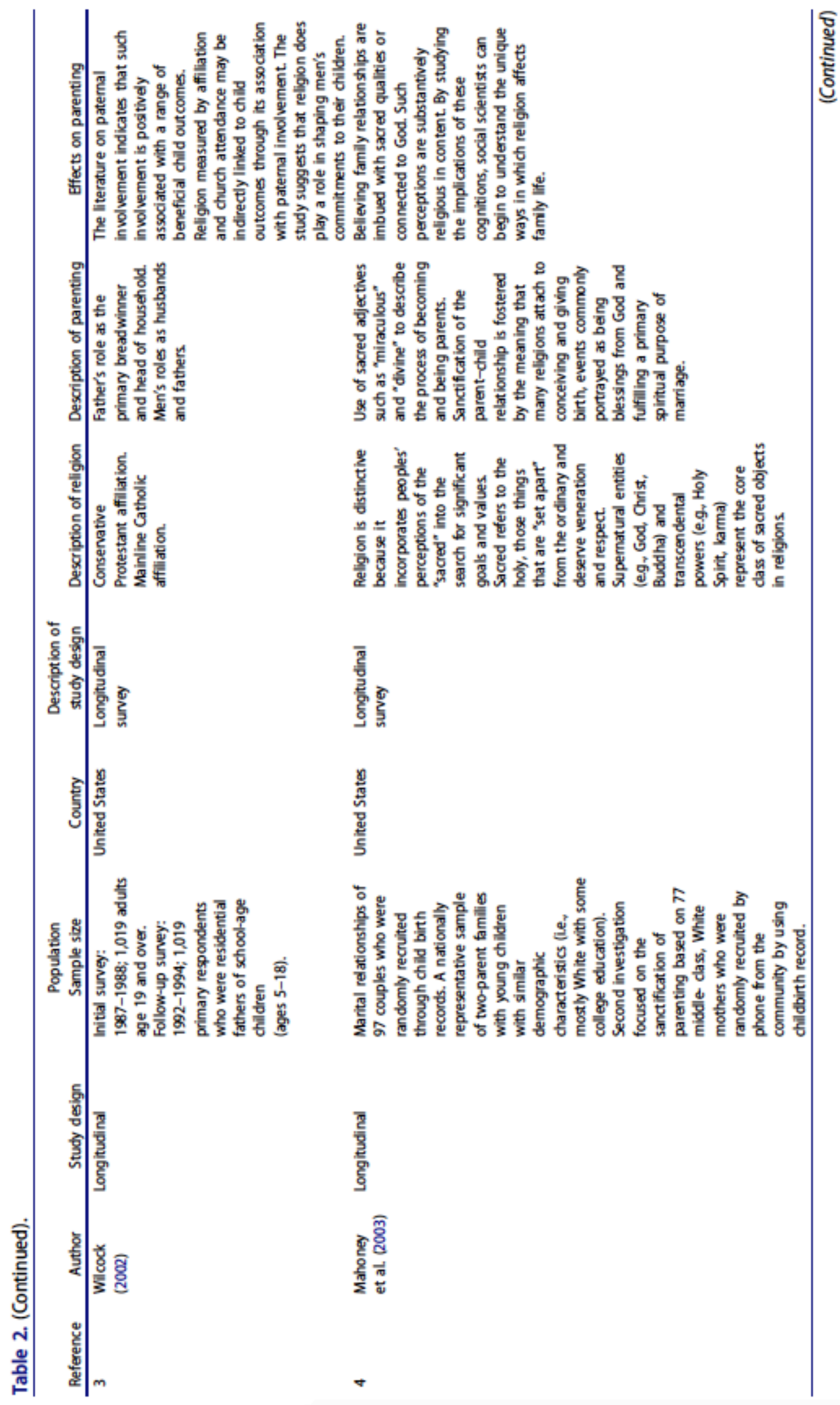




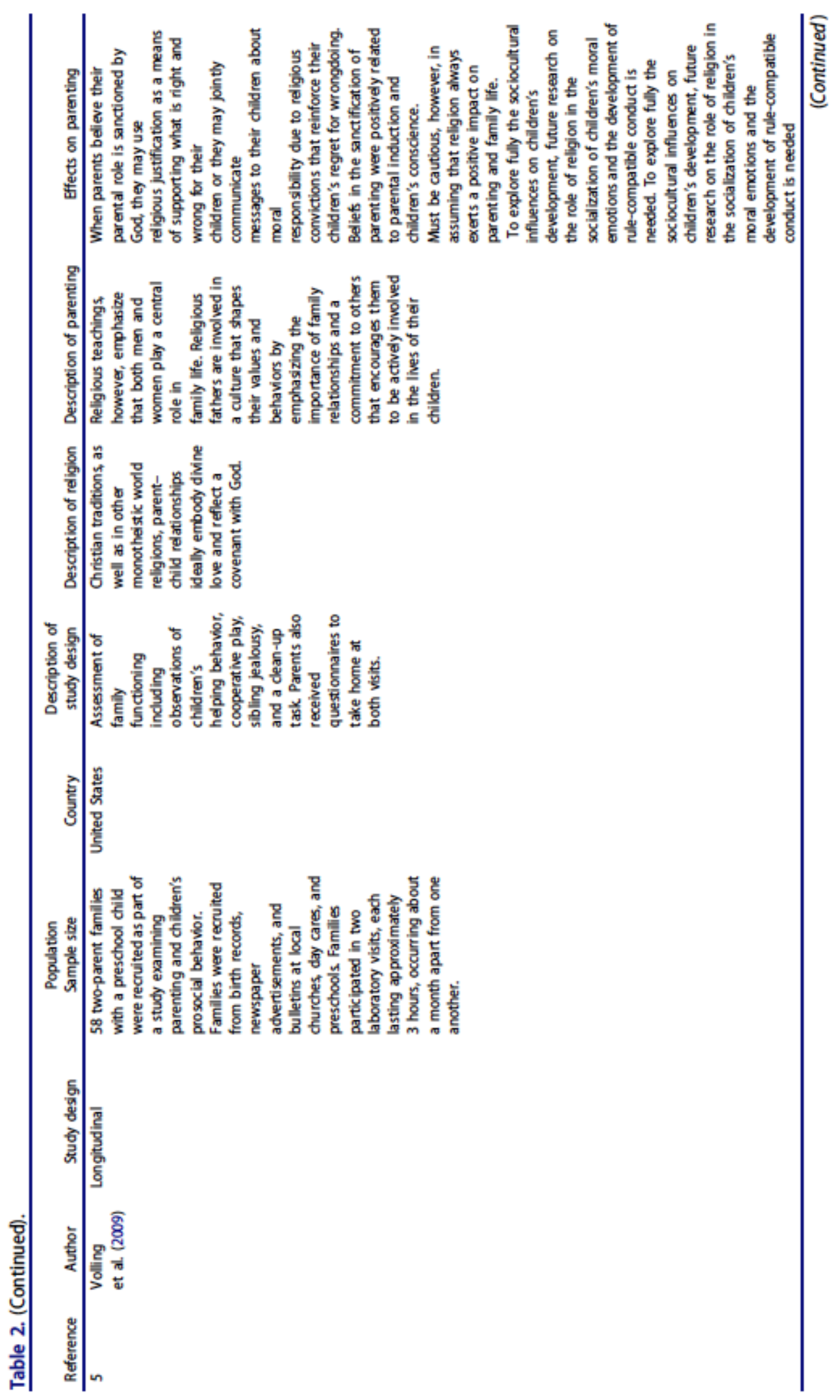




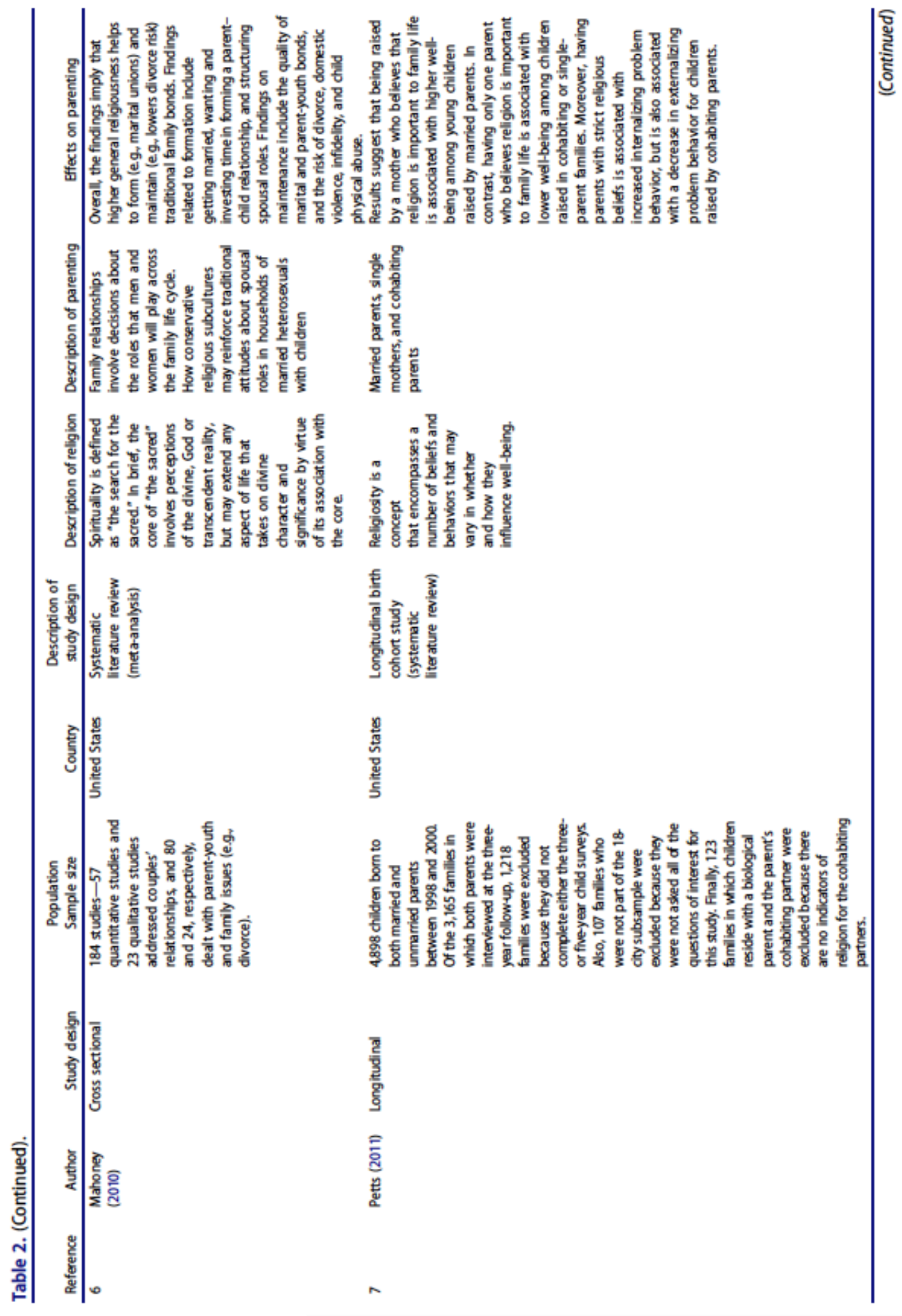

\section{http://repository.uwc.ac.za}




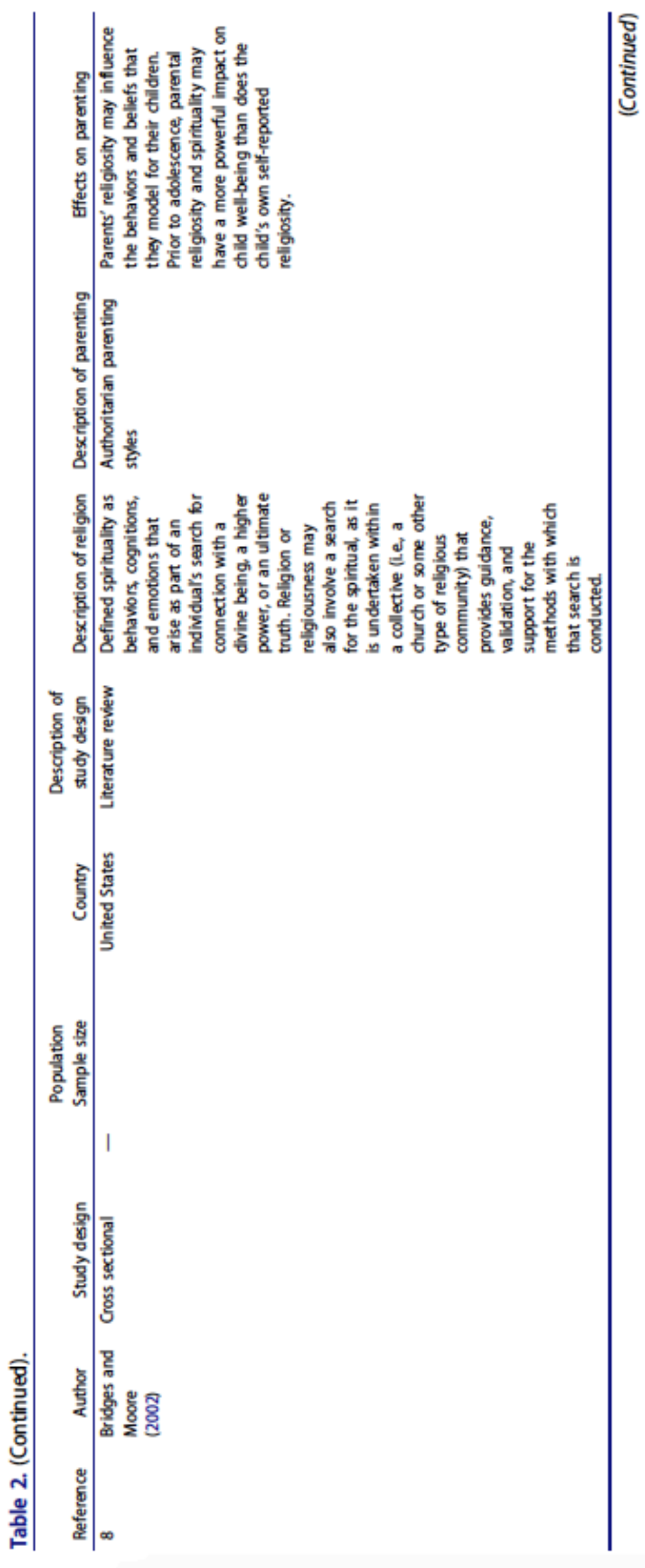

http://repository.uwc.ac.za 


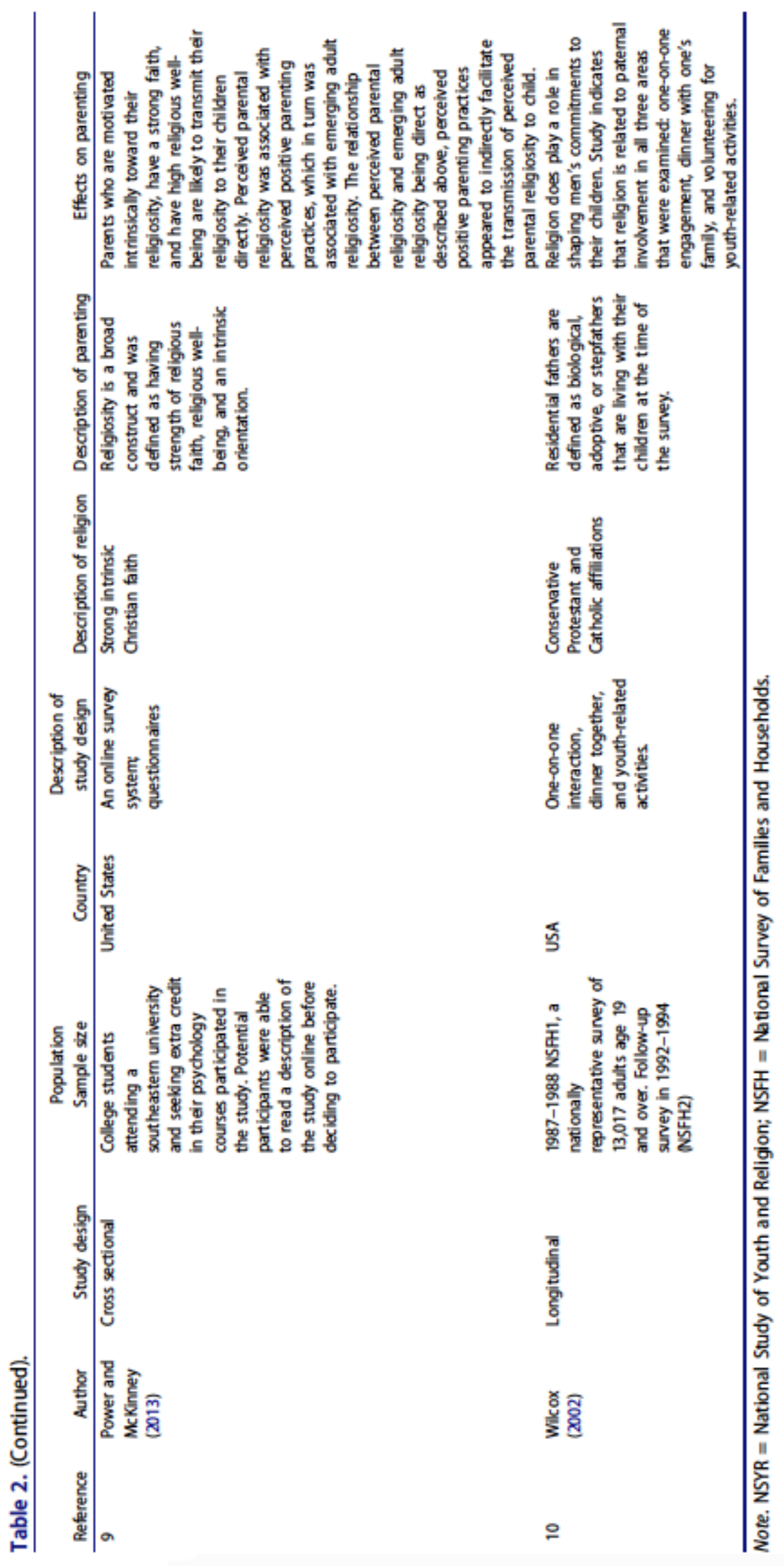




\section{The systematic review results}

The aim of this systematic review was to explore the effect of religion on parenting in order to guide parents in the way they parent. Parents' religiosity may influence the behaviors and beliefs that they model for their children. Particularly in the years prior to adolescence, parental religiosity and spirituality may have a more powerful impact on child well-being than does the child's own self-reported religiosity (Bridges \& Moore, 2002; Petts, 2011). It has been recognized that parents have a significant part to play in shaping the faith identity of children and engaging them in religious activities (Armet, 2009, Mahoney, 2003). Most parents saw religion as a way of life that was transmitted between generations. They considered it part of their par- enting responsibility to pass on their faith (Horwath, Lees, Sidebotham, Higgins, \& Imtiaz, 2008).

Parental church attendance and religious saliency may result in more cohesive family relationships. Positive effects are especially likely if religious congruence already exists between parents and child (Mahoney et al., 2001). When parents believe their parental role is sanctioned by God, they may use religious justification as a means of supporting what is right and wrong for their children or they may jointly communicate messages to their children about moral responsibility due to religious convictions that reinforce their children's regret for wrongdoing (Volling et al., 2009).

The literature on paternal involvement indicates that such involvement is positively associated with a range of beneficial child outcomes. A study by Wilcock (2002) suggested that religion plays a role in shaping men's commitment to their children. Religious teachings, however, emphasize that both men and women play a central role in family life. Religious fathers are involved in a culture that shapes their values and behaviors by emphasizing the importance of family relationships and a commitment to others that encourages them to be actively involved in the lives of their children (Volling et al., 2009).

Religion is a broad construct and plays an important role in adolescent identity formation by offering a transcendent worldview that grounds moral beliefs and behavioral norms in an ideological world view that gives meaning and orients behavior (Volling et al., 2009). Other types of religiosity, such as extrinsic orientations and spirituality, may demonstrate different effects. In particular, both Duriez et al. (2009) and Mahoney (2010) noted different findings based on different types of religiosity.

Parenting styles oriented to socialize children to accept religious values and norms do not occur in a vacuum, but rather are framed by the mutually reinforcing relationship between the family and religious institutions. Religious communities and traditions shape family formation, relations, and parenting practices (Armet, 2009). Further, parenting also is a broad construct and is defined as parents' attempts to raise children to be competent adults. Definitions of parental competence are shaped not only by broad cultural standards but also by immediate family circumstances (e.g., poverty, family structure) and membership in various subcultures (e.g., ethnic, religious). Overall, the findings imply that higher general religiousness helps to form (e.g., marital unions) and 
maintain (e.g., lowers divorce risk) traditional family bonds.

Findings related to family formation include getting married, wanting and investing time in forming a parent-child relationship, and structuring spousal roles. Findings on family maintenance include the quality of marital and parent-youth bonds, and the risk of divorce, domestic violence, infidelity, and child physical abuse (Mahoney, 2010). Results suggest that being raised by a mother who believes that religion is important to family life is associated with higher well-being among young children raised by married parents. In contrast, having only one parent who believes religion is important to family life is associated with lower well-being among children raised in cohabiting or single-parent families. Moreover, having parents with strict religious beliefs is associated with increased internalizing problem behavior, but is also associated with a decrease in externalizing problem behavior for children raised by cohabiting parents (Petts, 2011).

\section{Discussion}

While studies found positive correlations between religious conservatism, strict parenting, and nurture, they are limited in that no specific religious outcomes were measured (Armet, 2009). Children's affective discomfort about wrongdoing was also related to both parents' use of positive socialization strategies that involved praising the child's good qualities and making their approval conditional on the child's good behavior. These findings fit with prior theory and research indicating that parents' use of induction, gentle discipline, and a focus on reparation promote the child's emerging moral awareness (Grusec, 2006; Hoffman, 2000; Kochanska, 2002; Zahn- Waxler, Radke-Yarrowm, Wagner, \& Chapman, 1992). Consistent with the previous research, there is some evidence suggesting that religious homo- gamy may be beneficial for young children regardless of family structure (Bartkowski, Xu, \& Levin, 2008). Specifically, having two parents who frequently attend religious services is associated with lower levels of externalizing problem behavior. Having two parents who are religiously active increases the likelihood that children are exposed to and engaged in a moral community that may help to reinforce both parental and religious teachings, deterring young children from engaging in problem behavior (Myers, 1996; Smith \& Denton, 2005; Petts, 2011). However, being raised by parents from different religious backgrounds appears to provide some benefits for children (Petts, 2011).

The goal of the study was to have a better understanding of the effect of religion on parenting and whether parents' beliefs have an effect on the way they parent. Overall, results provide evidence that different aspects of parental religiosity may have positive and negative consequences for young children's well-being, and that these relationships may be conditioned by the family structure in which children reside. Religiously heterogamous families may have a greater level of tolerance and respect for others that helps children to feel secure and contributes to positive developmental behavior early in life (Petts \& Knoester, 2007). There is a good deal of historical evidence to suggest that religion possesses the capacity to socialize, motivate, constrain, and direct human assumption, values, preferences, moral commitments, choices and behaviors (Smith et 
al., 2002; Smith, 2003). Despite ample evidence that global indexes of religiousness are linked to family functioning, the mechanism by which religion influences family dynamics is not well understood or empirically documented (Pargament, 2005).

It is widely accepted that how parents relate to their children and how they communicate the demands they place on their offspring are of crucial importance not only for their children's general well-being but also for their internalization of values (Baumrind, 1996; Dudley, 2000; Eisenberg et al., 2005). There is conflicting evidence whether parental commitment to religious beliefs is likely to result in a harsh or warm parental style (Bartkowski \& Wilcox, 2000; Mahoney, 2010). Padilla-Walker and Thompson (2005), established that religious values that parents hold have a stronger impact on parenting tendencies that any other values parents hold. In a study conducted by Horwath et al. (2008) on the role of religious faith and religious practices on the parenting of adolescents, participants in the parents' focus groups frequently spoke of the influence their own parents continue to exert on them in adult life. They continually referred to ways in which their parents' religious beliefs had influenced their own approach to parenting and life choices.

It is noteworthy that although research on the beneficial effects of religiousness among adolescents has increased over the past decade, substantial gaps remain in our understanding of the role of religiousness in coping with family-related distress such as harsh parenting (Mahoney, 2013). Prior research suggests that parents shape their children's regulatory styles through sensitive caregiving in the absence of hostility (Eisenberg et al., 2001). Accordingly, it is expected that adolescents who receive harsh parenting would show poor self-control due to their experiences of poor-quality attachment, lack of warmth, and limited modeling.

Shor (1998) found that verbal abuse, such as swearing at a child, was not tolerated as it was considered to cause potential negative consequences for the child, whilst Bartkowski and Wilcox (2000) found that corporal punishment was advocated by Conservative Protestants over and above shouting at children. Harsh parenting, such as threatening, yelling, or screaming in response to misbehavior, is thought to contribute to more frequent externalizing behaviors that normalized violence or aggression (Catalano \& Hawkins, 1996). On the other hand, a community sample found that higher sanctification of parenting was linked to less spanking by biblically liberal mothers, though more spanking by biblical conservatives (Murray-Swank, Mahoney, \& Pargament, 2006). Biblically conservative parents cannot how- ever, be assumed to be excessively harsh. In fact, in a national survey, such parents reported yelling at their children less often than other parents (Bartkowski \& Wilcox, 2000). Studies demonstrate that harsh discipline is linked to behavior problems ranging from conduct disorder to depression and low self-esteem. For instance, researchers found that the use of harsh discipline by either parent in a two-parent household was related to greater adolescent depression and externalizing behavior (Bender et al., 2007). In contrast, according to Hoskins (2014) authoritative parents score high in responsiveness and demandingness and exhibit 
more supportive than harsh behaviors. Adolescents with authoritative parents are less prone to externalizing behaviors, and specifically are less likely to engage in drug use than individuals with uninvolved parents (Hoskins, 2014). Conversely authoritarian parents are low in responsiveness yet highly demanding. The authoritarian parenting style is associated with parents who emphasize obe- dience and conformity and expect that rules be obeyed without explanation in a less warm environment (Baumrind, Larzelere, \& Owens, 2010). Although literature on adolescent self-control in relation to harsh parenting is currently not available, research on children indicates that harsh parenting and potential for abuse are associated with poor self-control, which in turn is associated with internalizing and externalizing problems for children (Kim-Spoon, Cicchetti, \& Rogosch, 2013; Schatz, Smith, Borkowski, Whitman, \& Keogh, 2008).

According to Howarth and Lees (2010), traditionally and most notably in the United States, religious parents have tendency to be perceived as authoritarian in their approach to parenting, demanding obedience from their children in line with the requirements of their particular faith (Gunnoe, Hetherington, \& Reiss, 1999). However, Gunnoe et al. (1999) and Wilcox (1998), in studies of predominantly Christian families in the United States, found no association between religiosity and authoritarian parenting.

However, it appears that religious beliefs alone are unlikely to influence parenting style. For example, Danso, Hunsberger, and Pratt (1997) concluded that the right-wing authoritarian values and beliefs of "fundamentalist" [sic.] Christian participants in their study had a considerable influence on their child-rearing attitudes.

Some researchers have questioned whether higher levels of religiosity may lead to a more controlling parenting style. Danso et al. (1997) suggested that a greater parental goal of strong religious values for their children may mean that the parents are more likely to stress obedience. These researchers have hypothesized that very religious individuals may have a tendency toward a more rigid parenting style, and would thus parent in such a manner (Howarth \& Lees, 2010). In turn, strict parenting may inhibit the development of a healthy religious identity (Armet, 2009). In preventing a child from questioning and struggling would be to prevent them from developing a deep and mature commitment to their heritage (Fisherman, 2002). Christian parents it appears, commonly use an authoritarian parenting style, thereby impeding the child's religious development, and possibly resulting in harmful emotional outcomes as well.

Conversely the vast majority of research has found the authoritative parenting style to be a consistent predictor of positive adolescent outcomes. Although the research overwhelmingly indicates that parenting behaviors, such as parental warmth and control are associated with positive adolescent outcomes, studies using ethnically diverse samples have found variations in the relationship between parenting style and adolescent outcomes (Brody, Kogan, Chen, \& Murry, 2008). Research also suggests that parenting style and parental discipline behaviors affect adolescents differently based on cultural values among different ethnic groups within different types of communities. As mentioned 
earlier, authoritarian parenting practices in ethnic minority groups often have fewer negative effects on adolescent outcomes since it is considered normative and a valued socialization mechanism (Brody et al., 2008).

Parents are the "primary socializing agents for their children" (Flor \& Knapp, 2001, p. 627). Studies indicated that a child's religiosity tends to be similar to that of their parent and that membership of a religious community encourages social conformity (Flor \& Knapp, 2001; Gunnoe et al., 1999). There is, however, a notion that children and their parents should be treated as separate individuals. In order to achieve this, differences in child rearing, due to family structure, religion, culture, and ethnic origins, should be respected and understood (Department of Health; Home Office \& Education \& Employment, 2000). For example, the dominant religious beliefs of a society are likely to have a significant influence on structures, traditions, rituals, and ways in which life is conducted within that society (Gilligan \& Furness, 2006). In terms of mechanisms of internalizing parental behavioral standards, religion is a potential vehicle for internalization that has been largely overlooked in the research (Flor \& Knapp, 2001). Based on the conflicting evidence on parental religious beliefs, parenting styles, and child outcomes, the mechanisms through which these behaviors are internalized could be a point of departure for future research endeavors.

Hence, in light of the aforementioned studies there is clear evidence in terms of previous and current research that there is conflicting evidence whether parental commitment to religious beliefs is likely to result in harsh or warm parental styles. This is due to the fact that there are other factors such as culture, ethnicity, religious background, parental styles, character and upbringing, community structures, as well as family values, that play a significant role on how religion effects parenting and the religious upbringing of a child.

\section{Implications for practice}

Adolescence is a period of enormous adjustment for both teenagers and families. As children transition from childhood to adulthood, they go through many physical, emotional, and behavioral changes. Not surprisingly, many parents describe adolescence as the most difficult and anxiety-provoking period of their children's life. Although this systematic review was limited to focus on parental socialization patterns that were reinforced by their religious beliefs, there are obvious limitations to this approach. Having recognized these limitations, studies that emphasize a more inclusive social ecology, including family, friends, school, and the extended community, still find that parents continue to be the primary influence in shaping their children's religiosity, even when considering changes in maturity and increased autonomy that accompany young adulthood (Boyatzis \& Janicki 2003; Regnerus, Smith, \& Smith, 2004).

However, it would be short sighted to ignore the influence of social networks in the development of religiosity during adolescence. Friendship networks do 
matter and will continue to be a fruitful area of study, especially in areas of ambiguity. Gunnoe and Moore (2002, p. 621) for example, found that parent-peer influences were inverted to the degree that peer religiosity was a better predictor for adolescents while young adults were influenced by parents. Religion does not seem to be high on the list of priorities when it comes to scholars and professionals, especially those responsible for the welfare and safeguarding of children. The latter seems to lack awareness or training as to the role of religion in family life with many being unsure about dealing with the influence of faith on parenting. Beliefs in the sanctification of parenting were positively related to parental induction and children's conscience, however caution should be taken not to assume that religion always exerts a positive impact on parenting and family life (Volling et al., 2009).

Volling et al. (2009), further stated to explore fully the sociocultural influences on children's development, future research on the role of religion in the socialization of children's moral emotions and the devel- opment of rule-compatible conduct is needed. When families believe that their relationships are imbued with sacred qualities or connected to God, by studying the implications of these cognitions, social scientists can begin to understand the unique ways in which religion affects family life (Mahoney et al., 2003).

\section{Conclusion}

Religion, a broad construct plays an important role in adolescent identity formation. Parents' religiosity may influence the behaviors and beliefs that they model for their children. Particularly in the years prior to adolescence, parental religiosity and spirituality may have a more powerful impact on child well-being. Furthermore, religion does play a role in shaping men's commitments to their children. Religious fathers shape the values and behaviors of their children by emphasizing the importance of family relationships when they are actively involved in the lives of their children. Religious communities and traditions in turn shape family formation, relations, and parenting practices. Participants in the parents' focus groups frequently spoke of the influence of their own parents that continue to exert on them in adult life. They continually referred to ways in which their parents' religious beliefs had influenced their own approach to parenting and life choices.

It is clear from the systematic review that a lot of research has been conducted in terms of how religion affects parental styles and parenting relationships and also children and adolescents' well-being and behavior. The systematic review has shown that despite an increased interest in parenting in all sections of society, the research base that informs our understanding of religion is limited. It further shows that with interventions aimed at increasing specific skills and promoting greater understanding for the motivations of a child's behavior, parenting may significantly improve. Parenting skills are not innate and the task of parenting presents a significant challenge. Parenting nevertheless may be significantly improved with interventions aimed at increasing specific skills, and promoting greater understanding for the underlying motivations of a child's behavior. 


\section{References}

Armet, S. (2009). Religious socialization and identity formation of adolescents in high tension religion. Review of Religious Research, 50(3), 277-297.

Bader, C., \& Scott, A. (2006). Do as I say and as I do: The effects of consistent parental beliefs and behaviors upon religious transmission. Sociology of Religion, 67, 3313-3332.

Bartkowski, J. P., \& Wilcox, W. B. (2000). Conservative protestant child discipline: The case of parental yelling. Social Forces, 79, 265-296.

Bartkowski, J. P., Xu, X., \& Levin, M. L. (2008). Religion and child development: Evidence from the early childhood longitudinal study. Social Science Research, 37, 18-36.

Baumrind, D. (1996) The discipline controversy revisited. Family Relations, 45, 405-414. Baumrind, D., Larzelere, R. E., \& Owens, E. B. (2010). Effects of preschool parents' Power: Assertive patterns and practices on adolescent development. Parenting, 10, 157-201.

Bender, H. L., Allen, J. P., McEhaney, K. B., Antonishak, J., Moore, C. M., Kelly, H. O., \& Davis, S. M. (2007). Use of harsh physical discipline and developmental outcomes in adolescence. Development and Psychopathology, 19, 227-242.

Bridges, L. J., \& Moore, K. L. (2002). Religion and spirituality in childhood and adolescence. Bethesda, MD: Child Trends.

Brody, G. H., Kogan, S. M., Chen, Y. F., \& Murry, V. M. (2008). Long-term effects of the strong African American families program on youths' conduct problems. Journal Adolescent Health, 43, 474-481.

Brown, C. G. (2009). The death of Christian Britain: Understanding secularization, 18002000. London, UK: Routledge.

Catalano, R. F., \& Hawkins, J. D. (1996). The social development model: A theory of antisocial behavior. In J. D. Hawkins (Ed.), Delinquency and crime: Current theories (pp. 149-197). New York, NY: Cambridge University Press.

Coleman, J. C. (1997). The parenting of adolescents in Britain today. Children and Society, 11 (1), 44-52.

Danso, H., Hunsberger, B., \& Pratt, M. (1997). The role of parental religious fundamentalism and right-wing authoritarianism in child-rearing goals and practices. Journal for the Scientific Study of Religion, 36, 496-511.

Darling, N. \& Steinberg, L. (1993). Parenting style as context: An integrative model. Psychological Bulletin, 113, 487-496

Department of Health, Home Office and Department for Education and Employment. (2000). Framework for the assessment of children in need and their families. London, UK: Stationery Office.

Dudley, R. L. (2000). Why our teenagers leave the church. Hagerstown, MD: Review and Herald Publishing Association.

Duriez, B., Soenens, B., Neyrinck, B., \& Vansteenkiste, M. (2009). Is religiosity related to better parenting? Disentangling religiosity from religious cognitive style. Journal of Family Issues, 30(9), 1287-1307.

Eisenberg, N., Cumberland, A., Spinrad, T. L., Fabes, R. A., Shepard, S. A., Reiser, M., ... Guthrie, I. K. (2001). The relations of regulation and emotionality to children's 
externalizing and internalizing problem behavior. Child Development, 72(4), 11121134 .

Eisenberg, N., Zhou, Q., Spinrad, T. L., Valiente, C., Fabes, R. A., \& Liew, J. (2005). Relations among positive parenting, children's effortful control, and externalizing problems: A three- wave longitudinal study. Child Development, 76, 1055-1071.

Ely, C., \& Scott, I. (2007). Essential study skills for nursing. Edinburgh, Scotland: Elsevier.

Fisherman, S. (2002). Spiritual identity in Israeli religious male adolescents: Observations and educational implications. Religious Education, $97(1) 1)$, $61-799$.

Flor, D. L., \& Knapp, N. F. (2001). Transmission and transaction: Predicting adolescents' internalization of parental religious values. Journal of Family Psychology, 15, 627-645. Frosh, S. (2004). Religious influences on parenting. In Hoghughi, M. \& Long, N. (Eds),

Handbook of Parenting: Theory and Research for Practice (pp. 98-109). London, UK: Sage. Furman, L. D., Benson, P. W., \& Canda, E. R. (2004). A comparative international analysis of religion and spiritual social work: A survey of UK and social worker. Social Work Education, 24, 813-839.

Gershoff, E. T., Miller, P. C. \& Holden, G. W. (1999). Parenting influences from the pulpit: Religious affiliation as determinant of parental corporal punishment. Journal of Family Psychology, 13, 307-320.

Gilligan, P., \& Furness, S. (2006). The role of religion and spirituality in social work practice: Views and experiences of social workers and students. The British Journal of Social Work, 36(4), 617-637.

Godina, L. (2014). Religion and parenting: Ignored relationship? Child and Family Social Work, 19(4), 381-390.

Grusec, J. E. (2006). The development of moral behavior and conscience from a socialization perspective. In Killen, M., Smetana, J. G (eds), Handbook of Moral Development (pp. 243- 265). Mahwah, NJ: Lawrence Erlbaum Associates Publishers.

Gunnoe, M., \& Moore, K. (2002). Predictors of religiosity among youth aged 17-22: A longitudinal study of the national survey of children. Journal for the Scientific Study of Religion, 41(4), 613-622.

Gunnoe, M. L., Hetherington, E. M., \& Reiss, D. (1999). Parental religiosity, parenting style and adolescent social responsibility. Journal of Early Adolescence, 19, 199-225.

Harris, J. D., Quatman, C. E., Manring, M. M., Siston, R. A., \& Flanigan, D. C. (2013). How to write a systematic review. The American Journal of Sports Medicine, 42(11), 27612768. Higgins, J., \& Green, S. (2011). Cochrane handbook for systematic reviews of interventions version 5.1.0. The Cochrane Collaboration.

Hodge, D. R. (2005). Spirituality in social work education: A development and discussion of goals that flow from professional ethical mandates. Social Work Education, 24, 3735. Hoffman, M. L. (2000). Empathy and moral development: Implications for caring and justice. New York, NY: Cambridge University Press.

Horwath, J., Lees, J., Sidebotham, P., Higgins, J., \& Imtiaz, A. (2008). Religion, beliefs and parenting practices: A descriptive study. York, UK: Joseph Rowntree Foundation.

Howarth, J. \& Lees, J. (2010). Assessing the influence of religious beliefs and practices on parenting capacity: The challenges for social work practitioners. British Journal of 
Social Work, 40(1), 82-99.

Hoskins, D. (2014). Consequences of parenting on adolescent outcomes. Societies, 4, 506531. doi:10.3390/soc4030506

Kim-Spoon, J., Cicchetti, D., \& Rogosch, F. A. (2013). A longitudinal study of emotion regulation, emotion lability/negativity, and internalizing symptomatology in maltreated and nonmaltreated children. Child Development, 84(2), 512-527. doi:10.1111/j.1467-8624.2012.01857.x

Kochanska, G. (2002). Committed compliance, moral self and internalization: A mediational model. Developmental Psychology, 38, 339-351

Lees, J., \& Howarth, J. (2009). "Religious parents just want the best for their kids": Young people's perspectives on the influence of religious beliefs on parenting. Children \& Society, 23, 162-175.

Lipsey, M. W., \& Wilson, D. B. (2001). Practical meta-analysis, Applied Social Research Methods Series Vol. 49. Thousand Oaks, CA: Sage Publications

Mahoney, A. (2010). Religion in families, 1999-2009: A relational spirituality framework. Journal of Marriage and the Family, 72(4), 805-827.

Mahoney, A., Pargament, K., Murray-Swank, A., \& Murray-Swank, N. (2003). Religion and the sanctification of family relationships. Review of Religious Research, 44(3), 220236. Mahoney, A., Pargament, K., Tarakeshwar, N., \& Swank, A. (2001). Religion in the home in the 1980s and 1990s: A meta-analytic review and conceptual analysis of links between religion, marriage and parenting. Journal of Family Psychology, 15, 559-596.

Moher, D., Liberati, A., Tetzlaff, J., \& Altman, D., The PRISMA Group. (2009). Preferred reporting items for systematic reviews and meta-analyses: The PRISMA statement. Plos Med, 6(7), e1000097.

Murray-Swank, A., Mahoney, A., \& Pargament, K. I. (2006). Sanctification of parenting: Influences on corporal punishment and warmth by liberal and conservative Christian mothers. The International Journal of the Psychology of Religion, 16, 271287.

Myers, S. M. (1996). An interactive model of religiosity inheritance: The importance of family context. American Sociological Review, 61(5), 858-866.

Nye, M., \& Weller, P. (2012). Controversies as a lens on change. In L. Woodhead \& R. Catto (Eds.), Religion and change in modern Britain (pp. 34-54). London, UK: Routledge. Padilla-Walker, L. M., \& Thompson, R. A. (2005). Combating conflicting messages of values: A closer look at parental strategies. Social Development, 14, 305-323.

Petts, R. J. (2009). Trajectories of religious participation from adolescence to young adult- hood. Journal for the Scientific Study of Religion, 48(3), 552-571.

Petts, R. J. (2011). Parental religiosity, religious homogamy, and young children's well-being. Sociology of Religion, 72(4), 389-414.

Petts, R. J., \& Knoester, C. (2007). Parents' religious heterogamy and children's well-being. Journal for the Scientific study of Religion, 46(3), 373-389.

Phoenix, A., \& Husain, F. (2007). Parenting and ethnicity. York, UK: York Publishing Services Ltd.

Power, L., \& McKinney, C. (2013). Emerging adult perceptions of parental religiosity and 
parenting practices: Relationships with emerging adult religiosity and psychological adjust- ment. Psychology of Religion and Spirituality, 5(2), 99-109.

Regnerus, M., \& Burdette, A. (2006). Religious change and adolescent family dynamics. The Sociological Quarterly, 47(1), 175-194.

Regnerus, M. D., \& Smith, C. (2005). Selection effects in studies of religious influence. Review of Religious Research, 47(1), 23-50.

Regnerus, M., Smith, C., \& Smith, B. (2004). Social context in the development of adolescent religiosity. Applied Developmental Science, 8(1), 27-38.

Roman, N. V., \& Frantz, J. M. (2013). The prevalence of intimate partner violence in the family: A systematic review of the implications for adolescents in Africa. Family Practice, 30, 1-10.

Schatz, J. N., Smith, L. E., Borkowski, J. G., Whitman, T. L., \& Keogh, D. A. (2008). Maltreatment risk, self-regulation, and maladjustment in at-risk children. Child Abuse neglect, 32, 972-982.

Shea, B. J., Grimshaw, J. M., Wells, G. A., Boers, M., Andersson, N., Hamel, C., \& Bouter, L. M. (2007). Development of AMSTAR: A measurement tool to assess the methodological quality of the systematic reviews. BMC Medical Research Methodology, 7(10). doi:10.1186/1471-2288-7-10

Shor, R. (1998). The significance of religion in advancing a culturally sensitive approach towards child maltreatment. Families in Society, July-August, 400-409.

Smith, C. \& Denton, M. L. (2005). Soul searching: The religious and spiritual lives of American teenagers. New York, NY: Oxford University Press.

Smith, C., Denton, M. L., Faris, R. \& Regnerus, M. (2002). Mapping American adolescent religious participation. Journal for the Scientific Study of Religion, 41, 597-612

Smith, C. (2003). Religious participation and parental moral expectations and supervision of American youth. Reviews of Religious Research, 44, 414-424.

Streets, F. (2009). Overcoming a fear of religion in social work education and practice. Journal of Religion \& Spirituality in Social Work. Social Thoughts, 28, 144-160.

Thyer, B. A., \& Myers, L. L. (2009). Religious discrimination in social work academic programs: Whither social justice. Journal of Religion \& Spirituality in Social Work: Social Thoughts, 28, 144-160.

Vermeer, P., Jansen, J., \& Scheepers, P. (2012). Authoritative parenting and the transmission of religion in the Netherlands: A panel study. The International Journal for the Psychology of Religion, 22, 42-59.

Volling, B., Mahoney, A., \& Rauer, A. (2009). Sanctification of parenting, moral socialization, and young children's conscience development. Psychology Religion Spiritual, 1(1), 5368.

Whiting, R. (2008). No room for religion or spirituality or cooking tips: Exploring practical atheism as an unspoken consensus in the development of social work values in England. Ethics and Social Welfare, 2, 67-83.

Wilcock, W. B. (2002). Religion, convention, and paternal involvement. Journal of Marriage and Family, 64, 780-792.

Wilcox, W. B. (1998). Conservative protestant child-rearing: Authoritarian or authoritative? American Sociological Review, 63, 796-809. 
Younger, P. (2004). Using the Internet to conduct a literature search. Nursing Stand, 19(6), 45-51.

Zahn-Waxler, C., Radke-Yarrowm M., Wagner, E., \& Chapman, M. (1992). Development of concern for others. Developmental Psychology, 28, 126-136. 